\title{
The Assessment of Clinically Significant Differences in Treating Spinal Deformity Using the SRS Questionnaire: What Is the Threshold of Change That Is Meaningful to Patients?
}

\author{
SIGURD BERVEN, MD, ${ }^{1}$ MATTHEW BARON, MD ${ }^{2}$ VEDAT DEVIREN, MD, ${ }^{1}$ STEVEN GLASSMAN, MD ${ }^{3}$ \\ KEITH BRIDWELL, MD, ${ }^{4}$ KUSHAGRA VERMA, MD ${ }^{2}$ \\ ${ }^{1}$ University of California, San Francisco, San Francisco, California, ${ }^{2}$ University of Washington School of Medicine, Seattle, Washington, ${ }^{3}$ Norton Leatherman \\ Spine Center, Louisville, Kentucky, ${ }^{4}$ Washington University, St Louis, Missouri
}

\begin{abstract}
Background: The measurement of health-related quality of life is important in spinal deformity surgery. The Scoliosis Research Society questionnaire has allowed disease-specific research in this area, and determining the minimal clinically important difference (MCID) is as important as it is elusive. We seek to further refine our estimations of clinically perceived improvements by the patient.

Methods: We used an anchor-based approach for each domain of the SRS questionnaire to compare changes at 1 year after treatment. We set the MCID as the upper $95 \%$ boundary of the "no change" group bordering the "improvement" arm, where the patients may start to perceive their own change toward the better. We compared this with the mean change.

Results: The threshold value for the MCID was 0.54 for the pain domain, 0.31 for function, 0.62 for self-image, and 0.5 for mental health. The mean changes in our group's pain and self-image exceeded their MCID.

Conclusions: Compared with our previous work, we further attempted to refine our assessment of the MCID in spinal deformity. Pain continues to show clinically significant improvement, and self-image also demonstrated mean improvement over its estimated MCID.

Level of Evidence: 2

Clinical Relevance: This result in self-image is an important addition to the MCID literature, given its lack of consistency in previous work.
\end{abstract}

Other \& Special Categories

Keywords: MCID, adult deformity, SRS-22R, outcomes

\section{INTRODUCTION}

The measurement of health status provides a quantifiable ranking of an individual's self-assessment of well-being. The use of health-related quality-of-life (HRQOL) measures provides the foundation for an assessment of the utility of operative and nonoperative interventions and is the standard by which one may establish accountability for care and an evidence-based approach to health care. ${ }^{1,2}$ Health status may be measured by asking a general question of perception from the patient or by delving more specifically into the disease. $^{3}$ The Scoliosis Research Society (SRS)-22 has utility for clinicians and investigators as a disease-specific health status instrument that is responsive to health status over time and sensitive to nonoperative or operative interventions. ${ }^{4}$ The discriminate validity of the SRS-22 allows one to quantify changes attributable to the natural history over time, to compare different approaches to care, and to compare the value of health interventions within and between medical specialties. The demonstration of a positive and significant change in health status is crucial for the determination and justification of allocation of health care resources. ${ }^{1,5,6}$

As our treatments for spinal deformity evolve, it is important to establish a standard for measurement and interpretation of HRQOL data, along with a standard for change that is clinically relevant. Whereas some changes in HRQOL measures may 
Table 1. Distribution of diagnoses.

\begin{tabular}{lrc}
\hline Primary Diagnosis of Patients in the Analysis & n & Percentage \\
\hline Adult idiopathic scoliosis & 82 & 44.8 \\
Fixed sagittal imbalance-iatrogenic instrumented & 25 & 13.7 \\
Junctional degeneration & 23 & 12.6 \\
Adult de novo & 18 & 9.8 \\
Scheuermann's kyphosis & 6 & 3.3 \\
Fixed sagittal imbalance-other & 6 & 3.3 \\
Postlaminectomy kyphosis & 5 & 2.7 \\
Posttraumatic kyphosis & 4 & 2.2 \\
Fixed sagittal imbalance-ankylosing spondylitis & 4 & 2.2 \\
Congenital failure of segmentation & 3 & 1.6 \\
Congenital kyphosis & 3 & 1.6 \\
Fixed sagittal imbalance-iatrogenic postlaminectomy & 3 & 1.6 \\
Isthmic spondylolisthesis & 1 & 0.5 \\
Total & 183 & 100.0 \\
\hline
\end{tabular}

be statistically significant, if their magnitude is small, they may be unlikely to be meaningful. The minimal clinically important difference (MCID) is a threshold of change that is recognized by the patient as valuable and appreciable. ${ }^{1}$ The determination of MCID is often elusive and perhaps varies for different patient populations and various HRQOL measures.

Previous studies, including our own, have sought to determine the MCID for the SRS-22 using a variety of methods and a varying patient population. Whereas the MCIDs for pain, function, and total score seem to be reliably reported, the MCIDs for image and mental health remain poorly defined. ${ }^{7}$ The purpose of this article is to further define the MCID for the SRS-22 instrument from a sample of patients from multiple institutions. We aim to compare our results with previous studies and better define the MCIDs for the mental health and image domains.

\section{MATERIAL AND METHODS}

This is a prospective observational study of patients with spinal deformity. Patients were adults recruited from 3 different spine centers in the United States: University of California San Francisco, Leatherman Spine Institute, and Washington University. All were asked to complete the SRS-22 at their presentation. One year later, after operative or nonoperative treatment, they were asked to complete the SRS-30.

Methods for measuring MCID include anchorbased methods and distribution-based methods. The anchor-based approach uses an external criterion, or anchor, with which to compare change. The anchor is usually a global perception question regarding treatment effect and is patient centered. This contrasts with the distribution-based approach, which is dependent upon the variance within the sample and defines significance as a relationship between magnitude of change and variance. . $^{3,8,9}$

In this study, the anchor-based method was used to establish a MCID for each domain of the SRS questionnaire. The observed change in health status for each domain was compared with the patient's own global assessment of change at 1 year (the anchor). The change in health status was measured with specific questions assigned to domains for pain, function, self-image, and mental health, as seen as an adjunct in the expanded form, the SRS-30. For this study, the MCID in health status for each domain is defined as the value at the upper end of the $95 \%$ confidence interval of the group reporting "no change." We believe this may be where the patient could start to perceive their own change toward the better because it is bordering the "improvement" arm.

Paired-samples test analysis was used to determine statistical significance of changes in health status and standard errors of measurement (SEM). The paired sample analysis provided a value for a statistically significant difference in the cohort.

\section{RESULTS}

A total of 183 adults with spinal deformity (114 women, $69 \mathrm{men}$ ) were included by nature of presenting to one of the study's spine surgeons for evaluation and management of primary deformity involving the spine. The most common diagnoses were adult idiopathic scoliosis $(44.8 \%)$, iatrogenic sagittal deformity (13.7\%), and junctional degeneration (12.6\%; Table 1).

Paired-samples analysis demonstrated statistically significant improvements in health status for the cohort in each domain. The reported changes, along with their mean difference, SEM, and MCID values, are shown.

\section{Pain Domain}

Reports of pain improved by a mean of 0.8 and a SEM of 0.08 , from baseline to 1 year follow-up ( $P$ value $=.005$ ). The MCID was 0.54 (Figure 1 and Table 2). The change in pain exceeds the value of the MCID. 


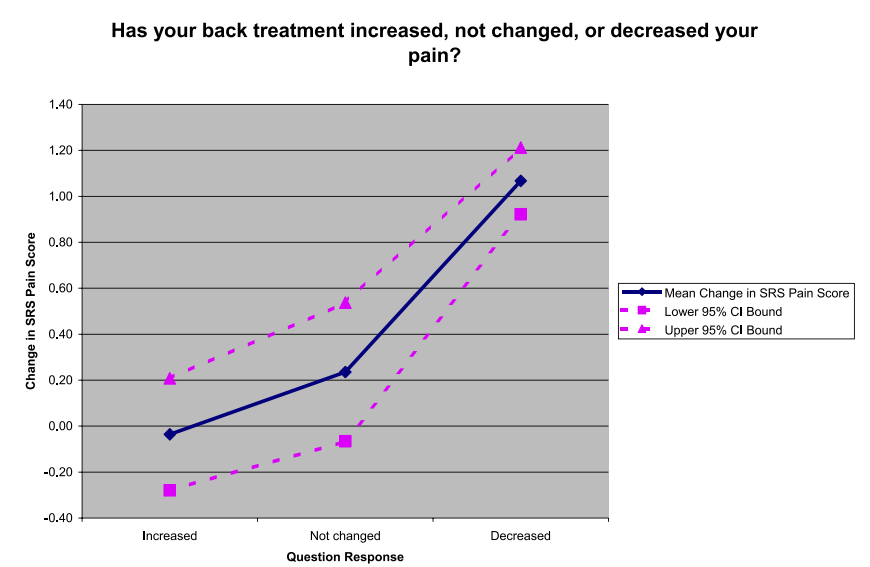

Figure 1. Pain.

\section{Function Domain}

Reports of function improved by a mean of 0.25 and a SEM of 0.065 , from baseline to 1 year followup $(P$ value $=.02)$. The MCID was 0.31 (Figure 2 and Table 2). The mean change in function is less than the MCID.

\section{Self-Image}

Reports of self-image improved by a mean of 1.1 and a SEM of 0.09, from baseline to 1 year followup $(P$ value $=.001)$. The MCID was 0.62 (Figure 3 and Table 2). This domain also exceeds the MCID.

\section{Mental Health}

Reports of mental health improved by a mean of 0.38 and a SEM of 0.062 , from baseline to 1 year follow-up $(P$ value $=.02)$. The MCID was 0.5 (Figure 4 and Table 2). This domain does not exceed the MCID.

\section{DISCUSSION}

This is a multicenter study of a prospective cohort of adults with spinal deformity. Statistically significant improvements were observed in each domain of health status over 1 year between baseline and follow-up. Using an anchor-based methodology, we

Table 2. Paired sample analysis.

\begin{tabular}{lcccc}
\hline $\begin{array}{l}\text { Health } \\
\text { Domain }\end{array}$ & $\begin{array}{c}\text { Minimal Clinically } \\
\text { Important } \\
\text { Difference (MCID) }\end{array}$ & $\begin{array}{c}\text { Observed } \\
\text { Change }\end{array}$ & SEM & $\begin{array}{c}\boldsymbol{P} \\
\text { Value }\end{array}$ \\
\hline Pain $^{\mathrm{a}}$ & 0.54 & 0.8 & 0.08 & .005 \\
Function $_{\text {Self-image }}^{\mathrm{a}}$ & 0.31 & 0.25 & 0.065 & .02 \\
Mental health $^{\text {Contal }}$ & 0.62 & 1.1 & 0.09 & .001 \\
\hline
\end{tabular}

${ }^{\mathrm{a}}$ Observed change exceeds the MCID.

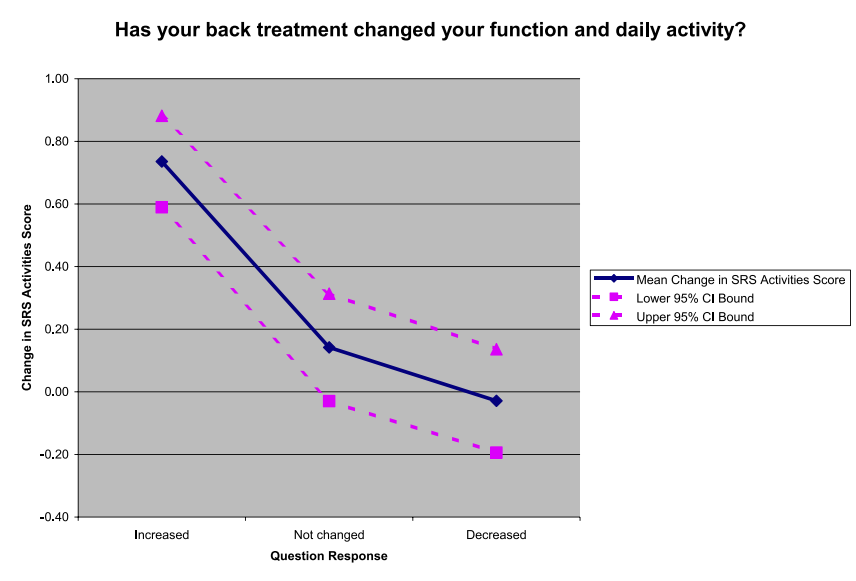

Figure 2. Function.

demonstrated a MCID for each domain. Clinically significant, or important, improvements were seen as being larger than their mean change. These occurred in pain and self-image.

The MCID has been previously studied regarding surgically treated adult deformity using the SRS questionnaire. Crawford et $\mathrm{al}^{7}$ reported that 1 year after their spinal deformity surgery, there was a generalized estimation of a 0.4 increase as their MCID, and less reliably shown for image and mental health domains. Carreon et $\mathrm{al}^{10}$ studied surgical deformity treatment in adolescents and found their MCID for pain to be less than ours (at $0.20)$ and their MCID for appearance to be higher than our findings (at 0.98). This is important, given Gum et $\mathrm{al}^{11}$ reported their 5-year follow-up satisfaction to correlate most with appearance score in the SRS questionnaire.

The utility of the SRS questionnaire as a diseasespecific health status instrument is that investigators can measure change in health status over time. The quantification of change permits one to assess the natural history and compare different approaches to care. One can then measure and place a value on the health intervention in a way that is meaningful to the patients' own global perception. A demonstration of a meaningful change in health status is crucial for the justification of health care resources.

This study provides an additional reference for thresholds of change that are clinically important to patients. Limitations in this study include the mixed cohort of nonoperative and operative patients and the selection of the value of the MCID. The mixed group was selected so that the changes were applicable for all patients being treated, regardless of the type of treatment. This heterogeneous cohort may be best applicable to the spine surgeon seeing 


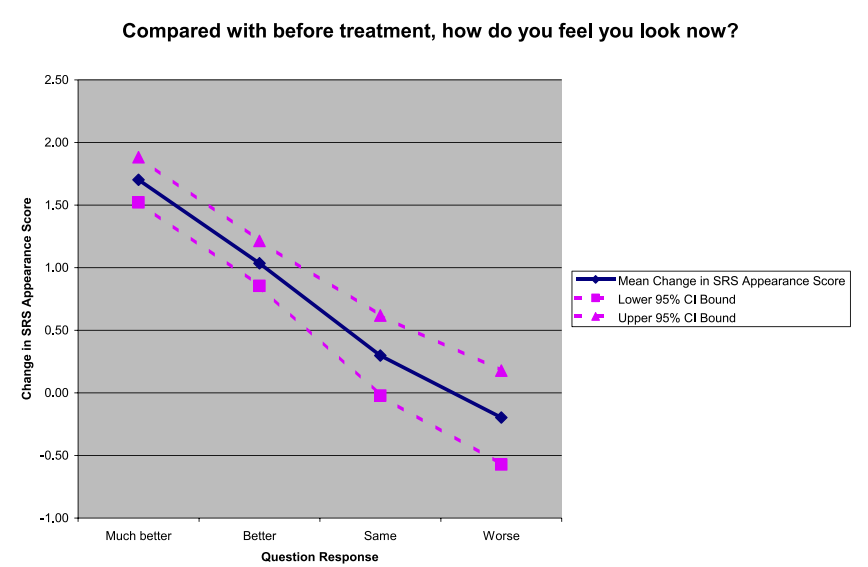

Figure 3. Self-image.

and assessing a patient for the first time, when the treatment may not yet be determined. This patient population would most certainly be heterogeneous in nature and could be initially counseled with values from this study.

Other limitations include considering that the value of the MCID could have been selected differently; for example, within the values of the "improvement" groups. However, mean improvement boundaries may not include the "minimal" clinically important difference. It was thought that the upper boundary of "no change" may be a more sensitive or representative value that suggests the trend toward improvement. This difference was less relevant for the subgroups that were not improving beyond the MCID. Further studies with anchorbased metrics and finer assessments of improvements will permit a more detailed delineation of the subset of patients who recognize a minimally important change in their health status.

The task of determining the true MCID for each domain of the SRS-22 remains a tedious task

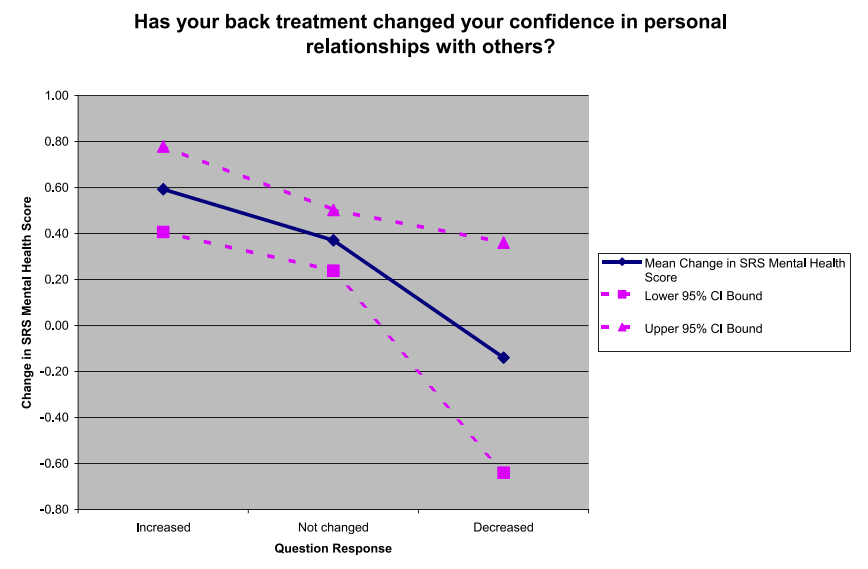

Figure 4. Mental health. requiring multiple studies that may or may not corroborate previous findings. Compared with our previous work, ${ }^{7}$ we were able to further define the MCIDs for self-image and mental health domains. We once again used an anchor based method to determine the MCID, with a heterogeneous treatment group and smaller size compared with our previous work. The determination of the MCID was done through an alternate method, and this brings diversity to this field of study.

\section{REFERENCES}

1. Beaton DE, Boers M, Wells GA. Many faces of the minimal clinically important difference (MCID): a literature review and directions for future research. Curr Opin Rheumatol. 2002;14(2):109-114.

2. Wells G, Beaton D, Shea BE, et al. Minimal clinically important differences: review of methods. $J$ Rheumatol. 2001;28(2):406-412.

3. Kelleher CJ, Pleil AM, Reese PR, Burgess SM, Brodish $\mathrm{PH}$. How much is enough and who says so? BJOG. 2004;111(6):605-612.

4. Berven S, Deviren V, Demir-Deviren S, Hu S, Bradford D. 9:46 Validation of the modified Scoliosis Research Society outcomes instrument (SRS-22) for adult deformity. Spine J. 2002;2(5):80.

5. Hägg O, Fritzell P, Nordwall A. The clinical importance of changes in outcome scores after treatment for chronic low back pain. Eur Spine J. 2003;12(1):12-20.

6. Wells G, Anderson J, Boers M, et al. MCID/Low Disease Activity State Workshop: summary, recommendations, and research agenda. J Rheumatol. 2003;30(5):1115-1118.

7. Crawford III CH, Glassman SD, Bridwell KH, Berven $\mathrm{SH}$, Carreon LY. The minimum clinically important difference in SRS-22R total score, appearance, activity, and pain domains after surgical treatment of adult spinal deformity. Spine (Phila Pa 1976). 2015;40(6):377-381.

8. Wyrwich KW. Minimal important difference thresholds and the standard error of measurement: is there a connection? $J$ Biopharm Stat. 2004;14(1):97-110.

9. Bagó J, Pérez-Grueso FJ, Les E, Hernández P, Pellisé F. Minimal important differences of the SRS-22 patient questionnaire following surgical treatment of idiopathic scoliosis. Eur Spine J. 2009;18(12):1898.

10. Carreon LY, Sanders JO, Diab M, Sucato DJ, Sturm PF, Glassman SD; and the Spinal Deformity Study Group. The minimum clinically important difference in Scoliosis Research Society-22 appearance, activity, and pain domains after surgical correction of adolescent idiopathic scoliosis. Spine (Phila Pa 1976). 2010;35(23):2079-2083.

11. Gum JL, Bridwell KH, Lenke LG, et al. SRS22R appearance domain correlates most with patient satisfaction after adult deformity surgery to the sacrum at 5-year follow-up. Spine (Phila Pa 1976). 2015;40(16):1297-1302.

Disclosures and COI: The authors received no funding for this study and report no conflicts of interest. The Institutional Review Board was 
through the Spinal Deformity Study Group and each center: University of California San Francisco, Norton Leatherman Spine Center, Washington University

Corresponding Author: Kushagra Verma, Beach Orthopaedics Specialty Institute, $3851 \mathrm{Ka}-$ tella Ave \#202, Los Alamitos, CA 90720. Phone:
(562) 206-0177; Fax: (562) 206-1576; Email: vermak01@gmail.com.

Published 30 April 2019

This manuscript is generously published free of charge by ISASS, the International Society for the Advancement of Spine Surgery. Copyright (C) 2019 ISASS. To see more or order reprints or permissions, see http://ijssurgery.com. 